\title{
Discursos interculturales y prácticas asimilacionistas: algunas contradicciones en el sistema educativo español
}

\author{
Intercultural discourses and assimilationist practices: some contradictions \\ in the spanish educational system
}

\author{
María Jiménez-Delgado / maria.jimenez@ua.es \\ Universidad de Alicante, España
}

\begin{abstract}
This article analyzes the degree of coherence amongst the legal, theoretical and formal speech about diversity management and the reality of the pedagogical practices in formal educational institutions. To that end is addressed a theoretical review of the different educational laws, the speeches of the teaching staff and educational practices from previous researches. The main result points to the existence of some contradictions: the concept of cultural assimilation at the same time that it is despised, both in educational legislation and in explicit and conscious teaching staff speech, ends up being the one adopted in most of the educational practices. This finding leads to some conclusions regarding the need to rethink and redefine the concept of cultural assimilation from the perspective of equality and a critical conception of ethnicity and identity.
\end{abstract}

Key words: Management of cultural diversity, educational legislation, educational practice, cultural assimilation, intercultural education.

Resumen: En este artículo se analiza el grado de coherencia entre el discurso legal, teórico y formal acerca de la gestión de la diversidad y la realidad de las prácticas pedagógicas en las instituciones educativas formales. Con este fin se aborda una revisión teórica de las distintas leyes educativas, de los discursos del profesorado y de las prácticas pedagógicas a partir de investigaciones precedentes. El principal resultado apunta a la existencia de algunas contradicciones: el concepto de asimilación cultural al mismo tiempo que se desprecia, tanto en la legislación educativa como en el discurso explícito y consciente del profesorado, acaba siendo el adoptado en la mayoría de las prácticas educativas. Este hallazgo conduce a algunas conclusiones respecto a la necesidad de repensar y redefinir el concepto de asimilación cultural desde la perspectiva de la igualdad y de una concepción crítica de la etnicidad y de la identidad.

Palabras clave: gestión de la diversidad cultural, legislación educativa, prácticas educativas, asimilación cultural, educación intercultural. 


\section{Introducción}

La presencia de un alumnado, con orígenes culturales diversos, en las aulas de los centros educativos españoles, ha ido progresivamente obligando a las instituciones educativas a tomar medidas políticas y pedagógicas para tener en cuenta esta realidad que es resultado de una sociedad mucho más plural. La falta de referentes propios es evidente, pues la situación de España como país de inmigración, que es la causa principal de esta pluralidad cultural en las escuelas, es muy reciente. En tan sólo veinte años ha cambiado significativamente la composición del alumnado. Las políticas públicas, así como más concretamente las educativas y pedagógicas, han buscado referentes fuera de las propias fronteras nacionales -en los llamados modelos anglosajón y francófono-. Por otra parte, esta realidad plural de las sociedades es común en todos los países de la Europa occidental y tiene importantes puntos de conexión con las situaciones resultantes de otros procesos migratorios en el norte del continente americano: en Estados Unidos y Canadá.

Sin embargo, a pesar de la transnacionalización de las migraciones y de las políticas europeas comunes - escasas y poco efectivas en estos temas-, cada sistema educativo nacional, a partir de su propio marco legislativo, diseña las propias políticas públicas y un modo concreto de gestionar esta diversidad cultural. Y este es el asunto que se tratará a continuación. Se parte de la realidad territorial descentralizada del Estado español y se investiga, con base en la revisión de las leyes educativas y de extranjería así como de investigaciones precedentes, la coherencia entre el discurso teórico y formal acerca de la gestión de la diversidad y la realidad de las prácticas educativas en los centros.

Resulta imprescindible estudiar las consecuencias de la multiculturalidad sobre los procesos de educación, de endoculturación, de socialización y de comunicación porque en la sociedad actual todos los individuos se enfrentan desde temprana edad a un contexto caracterizado por la pluralidad de referencias culturales. Es fundamental situar la diversidad en el seno mismo de los procesos sociales de cambio y comprender sus consecuencias en el mismo individuo, en los demás y en su entorno, porque uno de los problemas básicos, desde el punto de vista sociológico, que tiene que resolver toda cultura es el modo de relacionarse el individuo con la colectividad, como ya apuntó Elias (1990) en La sociedad de los individuos. 


\section{La gestión de la multiculturalidad y el concepto de ciudadanía}

Es bien conocido que el concepto de multiculturalismo, como modelo de gestión de la diversidad cultural, no es entendido de la misma manera en Europa que en Estados Unidos o Canadá. En Estados Unidos el nacimiento del multiculturalismo está unido a la lucha por los derechos civiles de los años sesenta y a las políticas de emigración del melting-pot que pretenden la integración de todos los emigrantes, independientemente de su condición y origen, en una misma cultura. En Canadá, el multiculturalismo aparece como concepto jurídico presente en la Carta Constitucional de 1982, aceptando el principio de doble pertenencia y considerando que puede favorecer la integración, y, por tanto, la igualdad de oportunidades. No obstante es necesario tener en cuenta que en el discurso oficial los términos multiculturalismo, integración e interculturalismo se yuxtaponen, mostrando la dificultad que supone en la práctica definir una realidad dinámica y compleja.

En Europa el término multiculturalismo hace referencia principalmente a las minorías, tanto étnicas como de origen inmigrante, que se pretende estén integradas en Estados-nación concretos. El multiculturalismo, como modelo de gestión de la diversidad cultural de inspiración anglosajona, permite al individuo pertenecer a una comunidad reconocida y distinta a la del Estado-Nación (Abdallah-Pretceille, 2001).

Cabe preguntarse cómo se define el concepto de ciudadanía desde el multiculturalismo y es especialmente Kymlicka (1996), filósofo canadiense, quien se ha ocupado con profusión de este asunto en su libro ya clásico titulado Ciudadania multicultural. Una teoría liberal de los derechos de las minorias. Como señala el autor, es necesario explicar cómo los derechos de las minorías, en las sociedades liberales, están limitados por los principios de la democracia, de la justicia social y de la libertad individual, no existiendo incompatibilidad entre el reconocimiento de la identidad cultural de las minorías étnicas a través de determinados derechos colectivos y los principios democráticos.

Kymlika (1996) se pregunta si podemos seguir hablando de ciudadanía en una sociedad en la cual los derechos se distribuyen en función de la pertenencia a un grupo. Para los liberales sería una contradicción, pues consideran que la ciudadanía, por definición, concibe a las personas como individuos con iguales derechos ante la ley. Ésta sería la posición de Rawls (1989), quien no admite la posibilidad de una ciudadanía diferenciada, ya que una sociedad donde los derechos dependen de la pertenencia religiosa o cultural, no reconoce el concepto de ciudadanía porque éste va indisociablemente vinculado 
al concepto de sociedad como sistema de cooperación justo y beneficioso para todas las personas reconocidas como seres libres e iguales.

Para Kymlika (1996), la ciudadanía diferenciada se define como la posesión de derechos poliétnicos, de representación o de autogobierno específicos en función del grupo. Esta misma definición, expresan los liberales, es preocupante en cuanto que favorece e incita a los grupos a la introversión y a centrarse en su diferencia. Sin embargo, la ciudadanía común, en contraposición de la ciudadanía diferenciada, no se define únicamente por un estatus legal común únicamente de derechos y deberes, y esto también lo admiten los liberales, sino por una identidad común, expresión de pertenencia a una misma comunidad política. Y aquí sí hay una diferencia, como señala Naïr (2010): el fortalecimiento de una identidad cívica y política común.

La preocupación de los liberales por el reconocimiento de los derechos étnicos y culturales tiene una poderosa razón y ésta es la estabilidad de los Estados, porque las democracias liberales necesitan de la solidaridad mutua entre los ciudadanos, y por ello es pertinente preguntarse si el reconocimiento político de las diferencias étnicas y culturales es compatible con ellas. Para Kymlika (1996) esta preocupación es exagerada, pues considera que las demandas de derechos colectivos de determinados grupos de inmigrantes o grupos que se sienten en desventaja social son demandas que tienen como fin una mejor y mayor inclusión y participación social.

Aun llegando a considerar esta afirmación plausible, lo fundamental es identificar los elementos que cohesionan la unidad en un estado democrático pluralista, porque lo incuestionable es la necesidad de este "sentimiento" de unión o vínculo social. Y es aquí donde la presente investigación se centra en uno de estos elementos considerado de una transcendental importancia para afrontar este reto: la educación, en cuanto que posibilita la construcción de esa ciudadanía común.

\section{Políticas públicas de gestión de la diversidad cultural en el sistema educativo español}

Con el fin de indagar sobre cómo se trata la diversidad cultural en el sistema educativo español, es preciso, en primer lugar, analizar el estado actual de las políticas públicas en materia de diversidad cultural, en el marco de un modelo político descentralizado, como lo es el español. Ha de tenerse en cuenta que se parte del reconocimiento de una realidad territorial diversa y pluricultural que se administra, en gran medida, desde los gobiernos autonómicos, y que permite valorar en qué medida la ejecución de un determinado modelo de 
gestión de la diversidad cultural, dentro del marco político descentralizado, puede conformar una nueva identidad de la política educativa.

A pesar del reconocimiento de la realidad plural y descentralizada del Estado español, es evidente el papel hegemónico del Estado en la regulación de los derechos fundamentales y las libertades públicas. Por lo tanto, existe una normativa básica desde la Administración Central referida a la gestión educativa de la diversidad cultural y otra autonómica basada en los principios de aquella.

Desde el punto de vista educativo, el Estado español se ha preocupado de garantizar el derecho a la educación y una política de igualdad de oportunidades. Así, es posible diferenciar tres etapas en las políticas públicas educativas referidas al fenómeno de la inmigración asociadas a diferentes leyes educativas: ${ }^{1}$ una primera, marcada por la institucionalización del fenómeno de la diversidad con el establecimiento de determinadas pautas de intervención; una segunda, que gestiona el fenómeno de la diversidad originada por la inmigración desde modelos educativos compensadores; y una tercera, que lo hace desde una interpretación amplia de la igualdad del derecho a la educación (Espejo, 2008).

$1^{a}$ etapa. La institucionalización de la diversidad. Es la etapa marcada por la Ley Orgánica del Sistema Educativo (LOGSE) de 1990 y por la Ley Orgánica de la Participación, Evaluación y Gobierno de los Centros Educativos de 1995. En estas leyes el tratamiento de la diversidad es en el marco de la compensación de desigualdades, en una década, la de los noventa, en la cual empieza a hacerse visible la población escolar inmigrante. Este hecho obliga al Estado a una mayor concreción normativa que desemboca en la formulación de un plan de actuación para garantizar a los hijos de los inmigrantes el acceso y la permanencia en el sistema educativo. Con este fin se desarrollan programas de adaptación y diversificación curricular y organizativa.

Se puede afirmar que esta primera etapa se define por la propuesta de un modelo educativo de tratamiento de la diversidad cultural que trata la diversidad con programas de refuerzo y compensación educativa y que, sin negar la identidad cultural de los inmigrantes, se orienta al aprendizaje de la lengua y la cultura del país de acogida con la finalidad de la integración social y la defensa de la igualdad social y educativa. Se opta así por ignorar las lenguas y culturas de origen de los alumnos con el fin de que no entorpezcan el proceso de adaptación a la cultura del país de acogida.

1 En 2013 se aprobó la LOMCE (Ley Orgánica de Mejora de la Calidad Educativa) que, previsiblemente abrirá una cuarta etapa. Es la séptima ley educativa de la democracia y la octava legislación en 43 años, ya que en 1970, cinco años antes del final del franquismo, se aprobó la Ley General de Educación (LGE). 
En la medida en que el sistema educativo ignora cualquier referencia lingüística o cultural de los alumnos de origen inmigrante, se opta por un modelo asimilacionista que pretende compensar las desigualdades -cuyo origen está en las carencias asociadas a las diferencias-, mediante intervenciones específicas que pueden provocar segregación, aunque todo ello se justifica desde la defensa de la igualdad. Este modelo tiene su origen en las teorías del déficit (Bereiter y Engelmans, 1966) como se explicará más adelante.

$2^{a}$ Etapa. Programas especificos de gestión de la diversidad cultural. Esta etapa está marcada por la Ley Orgánica de Calidad de la Educación (LOCE), aprobada en 2002 y que continúa con una política legislativa de mínimos, garantizando las prestaciones educativas básicas recogidas en la Constitución Española de 1978. Dicha ley anula el apartado específico de la LOGSE dedicado a la Compensación de las Desigualdades en Educación (título V) y lo sustituye por acciones orientadas a alumnos con necesidades educativas específicas. Se concreta en la habilitación de programas específicos de enseñanza de la lengua y cultura mayoritarias, impartidos en aulas específicas, y la segregación de los alumnos de más de quince años de edad, con problemas de adaptación a la Educación Secundaria Obligatoria (ESO) a programas de iniciación profesional.

$3^{a}$ Etapa. Planes integrales de educación. La Ley Orgánica de Educación (LOE) de 2006 se caracteriza por la preocupación por la equidad, por la calidad y por la convergencia de los sistemas formativos. La LOE considera que la compensación de desigualdades en educación debe estar dirigida a grupos de población que, por factores sociales, económicos, culturales, geográficos, étnicos o de otra índole, se encuentren en situación desfavorable.

Las políticas de integración del alumnado inmigrante pretenden facilitar el aprendizaje escolar, tanto desde el punto de vista de las relaciones sociales como desde el punto de vista curricular, posibilitando la adquisición de las competencias lingüísticas, con el fin de promover la cohesión con los sistemas formativos europeos. En definitiva, se pretende compensar desigualdades desde un modelo asimilacionista, aunque al mismo tiempo se explicite el respeto a la diversidad e identidad cultural del alumnado de origen extranjero.

\section{El tratamiento de la diversidad cultural en las Comunidades Autónomas}

Las políticas educativas autonómicas están condicionadas por el propio proceso descentralizador y por la orientación ideológica del gobierno autonómico (Bonal et al., 2005). Según Jiménez (2007), son tres los ejes que articulan las diferencias territoriales, que se relacionan tanto con planteamientos ideológicos 
como económicos: el primero sería el modelo de gestión público-privado de la educación, con una alta concentración de alumnado extranjero en la red pública, como es el caso de la Comunidad Valenciana. El segundo establece la relación entre políticas de calidad y políticas de igualdad, y el tercero hace referencia a la organización de la enseñanza de la religión en el marco escolar. Se constata, en definitiva, una desigual gestión de la diversidad según las Comunidades Autónomas, a partir del año 2000, cuando se afianza el cuerpo legislativo al respecto. En lo referente a la Comunidad Valenciana, al contrario que en otras Comunidades Autónomas como Cataluña o Andalucía, no hay una correlación entre el alto porcentaje de alumnado inmigrante y las medidas institucionales consecuentes, que tienen un escaso desarrollo reglamentario (Fernández et al., 2010).

Las medidas educativas se conciben, en su mayoría, desde la perspectiva compensatoria, y se refieren, en primer lugar, a la adquisición y consolidación de las competencias lingüísticas para el alumnado extranjero, y en segundo término, a la dimensión integradora de la diferencia a partir de medidas organizativas, curriculares y tutoriales que se sitúan entre modelos curriculares etnocéntricos y culturales relativistas o multiculturales con importantes desfases entre la teoría y la práctica, entre lo dicho y lo hecho (Martín, 2003).

No obstante, en la mayoría de los casos, hay cierta continuidad entre las políticas de las Comunidades Autónomas y las del Gobierno Central. En lo referente a la atención a la diversidad cultural del alumnado, predomina el concepto de compensación de desigualdades, a través de medidas lingüísticas, organizativas y curriculares. Así, todas las Comunidades Autónomas ofrecen apoyo lingüístico, de las lenguas oficiales, al alumnado inmigrante en aulas que reciben distintas denominaciones.

\section{Entre la asimilación y la integración: modelos de gestión de la diversidad cultural en el sistema educativo español}

Para conocer cuál es la situación en el Estado español, es útil partir de estudios realizados en España que analizan de forma exhaustiva las teorías y modelos existentes en relación con la gestión de la diversidad cultural y su concreción en distintas políticas educativas. Si bien ya se han esbozado someramente las políticas educativas, aquí se resumirán los modelos educativos existentes, situando el actual sistema educativo español próximo a alguno de ellos y desvelando las contradicciones, ya parcialmente vislumbradas entre la legislación, las teorías proclamadas y las prácticas realizadas. 
A partir de una investigación empírica en torno a cómo se aborda en los centros educativos españoles la diversidad lingüística y cultural, Martín (2003) concreta cuatro modelos educativos de gestión de la diversidad cultural situando al sistema educativo español próximo a alguno de ellos. Previo a presentar los resultados de su investigación es preciso describir dos teorías que surgen de la distinta forma de relacionar la diversidad y la desigualdad y de analizar las causas de esta última. Dichas teorías proponen diferentes soluciones referidas principalmente al tratamiento de las diferencias lingüísticas:

-La teoría del déficit. Nace en los años sesenta, a partir de las investigaciones de Bernstein (1989), sociólogo de la educación que explica el fracaso escolar de los más desfavorecidos a partir de déficits lingüísticos relacionados con déficits culturales y carencias económicas. Aceptando esta teoría con matices, a partir de las críticas realizadas por lingüistas como Labov (1985), se constata que quienes fracasan en el sistema educativo escolar tienen un conocimiento y uso limitado de registros o estilos lingüísticos y, consecuentemente, una menor movilidad social.

La teoría del déficit tiene como objetivo la eliminación de las diferencias, concebidas como causas de la desigualdad mediante una educación compensatoria dirigida a aquellos que presentan el hándicap o déficit lingüístico y/o cultural, en definitiva, académico. Ello supone la separación, aunque sea temporal, de estos alumnos del grupo. Dicho modelo pretende compensar desigualdades, pero para ello, en la mayoría de los casos, ignora las diferencias lingüísticas o culturales. Estas intervenciones específicas suelen ser segregadoras aunque la pretensión final es que faciliten la integración del alumnado, en este caso, procedente de la inmigración.

Normalmente, la aplicación de esta teoría del déficit en la escuela se hace de forma individual y no asociada a la pertenencia étnica o cultural, aunque, a veces, se corre el riesgo de generalizar el déficit a una clase social o a un grupo cultural o nacional concreto.

- La teoría de la diferencia pretende dar una respuesta alternativa a la teoría del déficit desde el ámbito de la lingüística, considerando que no se trata tanto de un déficit sino de una diferencia lingüística que se valora socialmente de forma positiva o no. Esta teoría pretende mantener las diferencias lingüísticas y culturales, como forma de luchar contra la desigualdad y el fracaso escolar.

Asimismo, propone incentivar las relaciones intergrupales y la creación de espacios comunes. Ha dado lugar a los modelos multiculturales e interculturales que, desde el punto de vista lingüístico, pretenden asegurar el aprendizaje de la lengua mayoritaria y vehicular en la escuela, sin ignorar o discriminar 
negativamente la lengua materna o vernácula, utilizándola como base para el aprendizaje de la segunda lengua.

El objetivo, por tanto, desde el punto de vista lingüístico es el bilingüismo. Desde esta teoría se entiende que los procesos de construcción de la identidad pasan necesariamente por el reconocimiento de las dos lenguas, al menos, la de origen y la académica o vehicular, y por crear espacios multiculturales en los centros, donde sea posible -porque esté permitido- el uso de otras lenguas, y exista la sensibilidad y la formación necesaria para que el profesorado no perciba su uso como un signo de aislamiento o de no integración a la sociedad receptora.

La teoría de la diferencia no parece tener una clara aceptación práctica en el sistema educativo español por las dificultades que entraña al plantear una mejor y mayor formación de los profesores, la necesidad de docentes de apoyo en el aula o la modificación del currículum y de la organización del centro. Esta transformación social que supone adoptar medidas de reparto del poder o de empoderamiento de las minorías lingüísticas y culturales no se ha producido en la práctica en la sociedad española.

Así, se pretende dar cuenta de los modelos educativos existentes a partir de la combinación de las respuestas que se dan a estas dos cuestiones: en qué medida la escuela facilita el mantenimiento de la identidad y las características culturales y lingüísticas minoritarias, en primer lugar, y, en segundo lugar, si se promueven o no las relaciones intergrupales (Martín Rojo, 2003).

Según se puede observar en la Tabla $1^{2}$ la doble respuesta negativa a las cuestiones planteadas da lugar a un modelo educativo compensatorio, mientras que la doble respuesta positiva da lugar a un modelo educativo intercultural. La diferente combinación positiva y negativa propicia, por un lado, un modelo educativo asimilador si promueve las relaciones intergrupales pero no el mantenimiento de la identidad cultural, y por otro, un modelo educativo multicultural si pone el énfasis en el mantenimiento de la identidad y de las características culturales y lingüísticas y no promueve las relaciones intergrupales.

\section{El modelo educativo asimilador}

Es el modelo que opta por el discurso de la igualdad a costa de la diferencia, ya que ésta se ve como una amenaza o un obstáculo para la integración de los individuos y para la cohesión social. La lengua común dominante permite la integración de todos los sectores sociales -minorías o clases sociales bajas-.

2 Esta tabla se puede consultar al final del artículo. 
Desde este planteamiento se considera que el reconocimiento de la diferencia puede ser causa de estigmatización, segregación y rechazo social y que, por tanto, es conveniente homogeneizar a partir de la lengua y cultura mayoritarias con el fin de igualar en derechos.

Desde el punto de vista lingüístico, ello supone sustituir la lengua materna por la lengua dominante para garantizar la igualdad de oportunidades. Este es el modelo francés donde todo tratamiento diferencial debido a la diversidad cultural de origen se considera discriminatorio. El mensaje a los/as hijos/as de los inmigrantes es que tienen que parecerse a los autóctonos para ser aceptados.

A partir este planteamiento asimilacionista, se entiende que se eliminan los problemas de discriminación y marginación de las minorías. La piedra angular es el concepto de integración (Aja et al., 1999), y ésta no es posible si no se da una redistribución del poder y una mejora de la posición de clase y económica de los inmigrantes. El proceso de aculturación o asimilación, si no va acompañado de una inserción y participación real del individuo en la sociedad, conlleva una desorientación personal de referentes y valores con consecuencias graves en la construcción de la personalidad del sujeto y en su adaptación y participación social (Carbonell, 1999).

El etiquetaje a los hijos de los inmigrantes - segunda generación o alumnos inmigrantes- puede ser una prueba de cómo, a pesar del modelo asimilacionista en vigor, las sociedades europeas los perciben como extraños; y cómo también parte de esta generación no se siente del país del que forman parte a pesar de poseer la nacionalidad española. ${ }^{3}$

Por otra parte, es necesario distinguir entre modelos asimilacionistas que instan al abandono y rechazo de la lengua y la cultura maternas, y los que no lo hacen. Aunque es cierto que la tendencia, en el caso del sistema educativo español, es la pérdida de la lengua de origen (Broeder y Mijares, 2003), acompañada, a veces, con cierta vergüenza y rechazo hacia la cultura familiar.

\section{El modelo educativo compensatorio}

Este modelo combina la asimilación con la segregación, creando en la escuela grupos que reciben una atención específica para tratar déficits concretos, de

3 El resultado de una encuesta realizada a 934 estudiantes de cuatro Institutos de Educación Secundaria con un alto porcentaje de alumnado de origen inmigrante (el $42 \%$ del alumnado entrevistado es de origen extranjero), dentro del Proyecto de Investigación ( $\mathrm{I}+\mathrm{D}+\mathrm{i}, \mathrm{GR}$ 12-20: 2013-2015) en curso: "Género, Educación e Igualdad (GEI)", así lo atestigua: el $58 \%$ de los estudiantes de origen extranjero se identifican con la cultura de origen de sus progenitores (investigación inédita, pendiente de publicación). 
forma que acaben alcanzando el mismo nivel que el grupo normal. Desde este modelo, la diversidad se percibe como fuente de desigualdad social y ésta se combate invisibilizando las diferencias a través del aprendizaje de la lengua y la cultura mayoritaria oficial.

Esta situación tiene como consecuencia la infravaloración de las lenguas y culturas propias de los alumnos de origen extranjero y su marginación. En la medida en la que no se consigan los objetivos asociados a la superación del déficit, principalmente lingüístico, la segregación puede hacerse definitiva y producir marginación, exclusión y fracaso escolar. Este modelo no suele explicitarse en las escuelas, pues está en las antípodas de lo que las leyes y las normativas vigentes declaran que ha de hacerse respecto al tratamiento de la diversidad.

Sin embargo, determinadas prácticas educativas, si bien minoritarias, se acercan a este modelo aunque no lo declaren de forma explícita. Así, una joven estudiante universitaria, hija de padres marroquíes, inmigrantes en España, declara (Jiménez-Delgado, 2012: 338):

Yo no sé leer árabe porque no he podido estudiarlo y claro, yo ahora mismo sí que me da mucha rabia y se lo reprocho a mis padres también, es que ¿por qué no me habéis enseñado?, tanto dices que hable mi idioma, ¿̨por qué no me habéis enseñado? Debería de darse en el instituto, al menos, como extraescolar, por supuesto.

\section{El modelo educativo multicultural}

Este modelo está vinculado a la teoría de la diferencia, ya que no pretende la asimilación cultural, sino trata de facilitar el mantenimiento de la identidad y de los rasgos lingüísticos y culturales diferenciales. Dentro de este modelo multicultural se sitúan los programas de enseñanza de la lengua y la cultura origen, que últimamente, en los países donde existen, se amplían a alumnos con otras lenguas de origen para evitar la guetización y como herramienta para la multiculturalidad.

Es el modelo de Canadá donde la Enseñanza de la Lengua y la Cultura de Origen (ELCO) ha ayudado a la percepción normalizada del multilingüismo y del multiculturalismo en la sociedad, al mismo tiempo que ha contribuido a mejorar la vinculación con la escuela y la sociedad canadiense de los alumnos de origen extranjero. Es interesante resaltar la evolución que ha habido en la sociedad canadiense, desde el rechazo de estos programas hasta su aceptación, incluso por parte de la tercera generación, en un fenómeno conocido como ethnic revival.

Hay en dicha situación dos aspectos dignos de ser destacados. Por un lado, existe ya previamente una integración lingüística, sociocultural y económica 
en la sociedad canadiense de esta generación; por lo tanto, el aprendizaje de la lengua y la cultura de origen no es una condición previa para la misma, variando, de este modo, sensiblemente su sentido. Por otro lado, ha habido un cambio importante en la denominación de estos programas de aprendizaje lingüístico, sustituyendo el término lengua de origen por lengua extranjera, término mucho más prestigioso y abierto que no apela al supuesto origen cultural de los individuos.

En el caso de España, a pesar de la legislación europea e internacional, y a pesar de determinados acuerdos como el firmado con Marruecos para la enseñanza de la lengua a los hijos de los inmigrantes marroquíes, no es una realidad ampliamente extendida. Cuando existe esta enseñanza, se hace en horario extraescolar y a través de convenios con algunas organizaciones no gubernamentales (ONG) o asociaciones, principalmente.

La enseñanza religiosa tampoco se hace efectiva pese a la ley Orgánica de Libertad Religiosa de 1980 y a los acuerdos concretos con algunas confesiones religiosas (Aja et al., 1999; MEC, 2014). Se perciben, sin embargo, actitudes paternalistas y folclóricas que desvirtúan la realidad multicultural (Carbonell, 1999) y que -lo más grave- fijan de forma obligada la identidad del otro, instándole a cumplir con el estereotipo asignado. Por otra parte, el modelo multicultural vincula la construcción identitaria únicamente a los orígenes familiares como si éstos fueran la única y la mejor fuente de construcción del yo.

\section{El modelo educativo intercultural}

Aunque se vincula también a la teoría de la diferencia, del mismo modo que el modelo multicultural, el contraste significativo está en que el modelo educativo intercultural pretende actuar en toda la comunidad educativa, no sólo en los hijos de los inmigrantes.

Ello implica la reorganización de los centros y del currículo incorporando conocimientos acerca de toda la diversidad cultural presente en las aulas y en el centro educativo. Este modelo pretende, como objetivo básico, la búsqueda de una identidad compartida (Naïr, 2010) para la convivencia plural, mediante el conocimiento mutuo y el cuestionamiento crítico de lo propio y de lo ajeno, lo cual implica el ejercicio de la crítica etnocéntrica y la aceptación del otro como interlocutor, con los mismos derechos y obligaciones. Es el reconocimiento de la ciudadanía para todos. Y ello supone que la sociedad mayoritaria esté dispuesta a repartir el poder, lo cual implica todo un proceso de aprendizaje democrático. 
Por lo tanto, en este modelo, la enseñanza de las lenguas y las culturas no puede limitarse a los grupos culturales minoritarios sino que ha de ofrecerse a toda la sociedad como medio para la adquisición de competencias comunicativas interculturales. En España, se echan en falta prácticas curriculares verdaderamente interculturales tal y como señalan distintos autores (Liégois, 1998; Torres, 1992; Peñalva, 2003; Álvaro, 2012).

\section{Hacia una necesaria reinterpretación de la asimilación cultural}

Después de la exposición de los modelos educativos más relevantes, y reconociendo que ninguno de ellos se puede materializar de forma pura ni en las políticas ni en las prácticas educativas, recuperaremos la cuestión formulada con anterioridad acerca de qué modelo o conjunción de modelos se pueden reconocer en las políticas educativas españolas y en las prácticas pedagógicas.

Para ello, se parte del concepto de asimilación cultural (Terrén, 2005), con la finalidad de explicar por qué es un modelo que al mismo tiempo que se desprecia, acaba siendo el adoptado en la mayoría de las prácticas educativas (Martín, 2003), especialmente aquellas dirigidas a la población escolar multicultural.

Como ya se ha empezado a vislumbrar, la asimilación cultural es una cuestión central cuando se investiga sobre los procesos de socialización e integración social de los hijos y las hijas de los inmigrantes. En España, desde la sociología de la educación, se ha empezado a estudiar el tema a partir de los años noventa, constatando una clara inclinación a denostar la asimilación cultural como una forma de integración equivocada, pues implica la renuncia a una supuesta identidad y diferencia culturales. Frente a esta fallida integración se defiende la interculturalidad como buena forma de participación social.

Es cierto, por otra parte, que es relativamente reciente la investigación sociológica sobre la descendencia de la inmigración y sobre la gestión política y educativa de esta mayor pluralidad social, aunque en los últimos años ha tenido un rápido crecimiento en España (Terrén, 2005). Esta falta de tradición y de investigaciones empíricas propias ha traído consigo la importación de modelos, para explicar los nuevos procesos de incorporación a la sociedad española de los inmigrantes y de sus descendientes, y uno de esos modelos importados ha sido el de la asimilación.

Es fundamentalmente de la tradición investigadora norteamericana de donde se apropia el concepto de asimilación sin haber tenido tiempo para verificar su validez práctica, debido a la recientísima presencia de las "segundas 
generaciones" en nuestro país. Es así que antes de ser investigado en el nuevo contexto, este modelo de gestión de la diversidad es denostado, abrazándose acríticamente los modelos multicultural y/o intercultural.

De este modo se percibe la asimilación cultural como una integración social malograda, pues implica renunciar a la supuesta diferencia cultural, con las consecuencias de pérdida de autoestima y dignidad. En el polo opuesto estaría la buena integración intercultural. Así lo atestiguan algunos estudios que definen como resultados no demasiado positivos aquellos en los cuales la mayoría del profesorado acaba defendiendo en la práctica el paradigma asimilacionista en vez del intercultural (Matencio-López et al., 2015: 187).

Existen razones históricas -fundamentalmente un pasado homogeneizador marcado por la dictadura franquista- que invitan a desconfiar de políticas que no hagan énfasis en el respeto de la diversidad y que no reivindiquen la pluralidad lingüística y cultural de cada una de las Comunidades Autónomas en las que se vertebra el Estado español. Frente al orden basado en la homogeneidad cultural, que se percibió en su momento como resultado de un poder político represivo, y que la sociología crítica señaló como causante de las desigualdades sociales y educativas, surge la exaltación de las diferencias culturales como un proceso liberador, y consecuentemente la asimilación cultural, entendida como devenir similar (Brubaker, 2001) a la población autóctona, es denostada por los sociólogos críticos y por los sectores políticos progresistas.

Se ha producido una irreflexiva reivindicación de lo diverso, que entiende la diversidad como una riqueza en sí misma, como si fuera un bien cultural estático y físico que está necesitado de una especial protección para que no llegue a desvirtuarse o corromperse (Terrén, 2005). Ello explica algunos contradictorios discursos y prácticas de exaltación de la diferencia.

En España, desde la pedagogía más sociológica, que proponía una teoría crítica del currículo, se denostaban las políticas educativas asimilacionistas e integracionistas o compensatorias y se criticaba el modelo del melting-pot norteamericano por considerarlo un modelo de imperialismo cultural. Según Terrén (2005), en este contexto, el concepto de asimilación cultural se interpreta como reproducción cultural, en tanto que la escuela, como aparato ideológico del estado capitalista, desde el enfoque althusseriano, sólo produce integración cultural ignorando o suprimiendo todas las diferencias o particularidades que cuestionen la ideología dominante.

De esta interpretación reproduccionista, más ideológica que científica, surge la idolatría de la diversidad (Savater, 2004), y este eslogan repetido hasta la saciedad como un mantra en las escuelas españolas: "La diversidad 
enriquece", aunque en la práctica la actividad docente lo contradiga, pues resulta ser asimilacionista, en la mayoría de los casos, aunque con apariencia multiculturalista como atestigua una profesora de un instituto de educación secundaria (Jiménez- Delgado, 2012:360):

Es que a veces nos quedamos en los actos folclóricos que a mí me está dando vergüenza. Que vamos que, claro, yo tampoco soy flamenca. Ni quiero que me asocien con el flamenco... Y además, fijar así estereotipos no ayuda... Lo más intercultural que hicimos fue lo de la Constitución, que escriban las Constituciones de sus países de origen: cosas más integradoras, pero no desde el folclore. Pero no es la voluntad de todo el centro, de todo el profesorado. Más bien es la voluntad personal de algunos.

En la línea de lo antes expresado por Savater, el discurso educativo mayoritario es excesivamente monótono con el concepto de diversidad anteponiéndolo al de asimilación por considerar a este último homogeneizador. Sin embargo, urge preguntarse por qué la elección de mantener la identidad cultural es tan respetable y debe ser promovida en la escuela, mientras que la elección de asimilarse, en el sentido de compartir ciertos valores de la sociedad mayoritaria, no lo es tanto e incluso se interpreta como un fracaso en el proceso de integración.

Es, pues, necesario reinterpretar el concepto de asimilación cultural. Para ello, hay que reconsiderar la visión simple y esencialista de la dinámica cultural que parte de una concepción de la identidad y de la etnicidad estática y cerrada. Porque la actual teoría de la etnicidad (Terrén, 2005) reconoce el carácter cambiante y fluido de las identidades en el contexto de la globalización, que propicia intercambios diversos con el resultado de nuevas construcciones identitarias mucho más flexibles, fluidas y dinámicas (Thomas, 2004; Bauman, 2006).

Por otra parte, esta concepción simple y cerrada de la identidad cultural está asociada a una concepción también muy limitada y estática de los procesos de socialización. El esquema reproduccionista del antiasimilacionismo define la socialización desde una perspectiva más intergeneracional que intrageneracional ignorando así las poderosas y múltiples influencias socializadoras en un mundo globalizado como el actual, al mismo tiempo que infravalora el papel activo del individuo en estos procesos.

Por otro lado, desde el reproduccionismo se analizan los procesos de asimilación cultural desde la perspectiva de una dicotomía excluyente como es la que se establece entre cultura de acogida versus cultura de origen. Este es, por tanto, un modelo binario de identidad cultural excesivamente simplista. Dicha tesis, sin embargo, es superada desde la perspectiva sociológica reflexiva representada por sociólogos contemporáneos como Beck (1997), 
Giddens (1997), Castells (2003) y Touraine (2002), especialmente por este último, cuando parte del concepto de individuo como actor social y sujeto a un mismo tiempo.

Ya Park y Burgess (1970), en la segunda década del siglo XX, definían la asimilación como un proceso de disolución de signos externos que produce una homogeneidad superficial -en las modas, en los modos- perfectamente compatible con diferencias de criterio y actitud. Como indica Terrén (2001: 100), explicando el concepto de asimilación de Park, "los contextos modernos tienden al cosmopolitismo y precisan homogeneidad para propiciar una movilidad individual y unos contactos que sin ella se verían impedidos por los tabúes y el conservadurismo de los prejuicios".

Esta homogeneidad secundaria o superficial es para Park (1970) una condición de aplicación del principio de laissez-faire, laissez-aller porque establece una solidaridad elemental que permite a los individuos de mentes diferentes coordinar su acción y dotar de carácter corporativo al grupo. Después de todo, la capacidad de movimiento independiente era para Park (1970) la base y el símbolo de toda otra forma de independencia.

La asimilación propicia dos tipos de solidaridad y vinculación social distintos que diferencian a las sociedades premodernas de las modernas. Las primeras se basan en los vínculos primarios y las modernas en los vínculos secundarios.

Ello significa que los fundamentos de la vida social y de la interdependencia cambian en las modernas "sociedades cívicas", en las cuales, a diferencia de las sociedades premodernas, lo que importa y es relevante es la ciudadanía y no el parentesco. Debe insistirse en que esta concepción de la asimilación, situada en un momento sociohistórico distinto al actual, contiene ya el germen de la ciudadanía por encima de la pertenencia familiar y cultural.

Situados en una época y contexto geográfico distintos al de Park (1970), al concepto de ciudadanía propio de la modernidad, hay que añadir el de transnacionalismo (Portes, 2004), como proceso de ida y vuelta que permite, en un mundo global como el nuestro, el continuo trasiego extraterritorial, posibilitando a los hijos y a las hijas de los inmigrantes especialmente, una doble o incluso múltiple presencia entre sociedades y culturas distintas como puede ser la de origen y la de acogida.

Por esa razón, aunque la emigración sea un asunto familiar, como ha señalado Siguán (1998), el peso de los iguales y del mundo global y plural en la adolescencia y juventud es mayor que en sus progenitores, debilitándose así las identidades heredadas. 
Los diferentes tipos de asimilación (Portes y Rumbaut, 2010) darán lugar a distintas formas de adaptación, de participación o de integración de los hijos y de las hijas de los inmigrantes a la sociedad de acogida.

\section{Algunas conclusiones y propuestas}

Después de haber analizado los modelos de gestión de la diversidad cultural existentes -tanto desde su dimensión histórica y formulación teórica, política y también ideológica, como desde su realidad social práctica-, la conclusión más importante es que es necesario partir de modelos de socialización nuevos, más flexibles, plurales y horizontales, así como de concepciones críticas de la etnicidad y de la identidad, pues a menudo se asume acríticamente y de forma paradójica "un repliegue identitario, en el marco de un proceso de culturalización del mundo que concede un valor desmedido a categorías culturales o civilizacionales a la hora de definir la pertenencia de individuos y comunidades" (Rodríguez, 2011: 92).

Desde esta nueva perspectiva, que asume el reto de redefinir desde nuevos parámetros los conceptos de socialización e identidad, la asimilación cultural se define como un proceso complejo, en contacto con múltiples variables, muchas de ellas ajenas a las características asociadas al origen familiar o a la nacionalidad de procedencia de los mismos menores y de sus padres, porque todas las variables que influyen en el proceso de incorporación social no se pueden aislar ni controlar. Así, el peso de un factor depende de la configuración de relaciones sociohistóricas en que se inserta. La influencia del género, del nivel de estudios o de la clase social, se relaciona con otras características secundarias (Martín Criado, 2010).

Es fundamental, en el necesario debate sobre la gestión de la diversidad cultural que todavía se ha de dar en España, introducir elementos de análisis como el de la igualdad, demasiadas veces ignorada por el protagonismo del derecho a la diferencia. Esta teoría de la diferencia, en exceso defendida y justificada por el modelo multicultural, también está ocupando un lugar demasiado central en el modelo intercultural, olvidando otros debates mucho más importantes: los que deben decidir sobre la igualdad entre varones y mujeres; entre autóctonos y foráneos, y, en definitiva, sobre la libertad individual frente a los intentos de imposición del comunitarismo.

Para ello, han de utilizarse, en los centros educativos -tanto en sus formas organizativas y de gestión como en el currículo- las herramientas propias de una democracia: el diálogo, la reivindicación y la protección, disfrute y cumplimiento de los mismos derechos para todos, es decir, el igual acceso a 
la ciudadanía. Y dado que en la misma concepción de la democracia (Sartori, 2003) está la ampliación de sus propios límites, o dicho de otra forma, su perfectibilidad, es justo y necesario no conformarse con sus actuales fronteras.

\section{Bibliografía}

Abdallah-Pretceille, Martine (2001), La educación intercultural, Barcelona: Idea Books. Aja, Eliseo et al. (1999), La inmigración extranjera en España: los retos educativos, Barcelona: Fundación "la Caixa".

Bauman, Zygmunt (2006), Comunidad. La búsqueda de refugio en un mundo hostil, Madrid: Siglo XXI.

Beck, Ulrich (1997), Modernización reflexiva: politica, tradición y estética en el orden social moderno. Madrid: Alianza.

Bereiter, C. y S. Engelmans (1966), Teaching Disadvantage Children in the Pre-School, Nueva York: Prentice Hall.

Bernstein, Basil (1989), Clase, código y control, Madrid: Akal.

Bonal, Xavier et al. (2005), La descentralización educativa en España, Barcelona: Fundació Carles Pi y Sunyer.

Broeder, Peter y Laura Mijares (2003), Plurilingüismo en Madrid. Las lenguas de los alumnos de origen inmigrante, Madrid: Centro de Investigación y Documentación Educativa (CIDE).

Brubaker, Rogers (2001), “The return of assimilation? Changins perspectives on immigration and its sequels en France, German and the United States", en Ethnic and racial studies, núm. 24, vol. 4, Oxford: Routledge.

Carbonell, Francesc (1999), "Desigualdad social, diversidad cultural y educación", en Aja, Eliseo et al., La inmigración extranjera en España: los retos educativos, Barcelona: Fundación "la Caixa".

Castells, Manuel (2003), El poder de la identidad. Madrid: Alianza.

Elias, Norbert (1990), La sociedad de los individuos, Barcelona: Península.

Espejo, Lourdes Belén (2008), "El fenómeno de la emigración en España y en las políticas educativas territoriales”, en Revista Española de Educación Comparada, núm. 14, Madrid: UNED.

Fernández, Mariano et al. (2010), Fracaso y abandono escolar en España, Barcelona: Fundación "la Caixa".

Giddens, Anthony (1997), Modernidad e identidad del yo: el yo y la sociedad contemporánea. Barcelona: Península.

Jiménez, Jesús (2007), "Balance de una legislatura", en Cuadernos de Pedagogía, núm. 367, Barcelona: WoltersKluwer.

Kymlicka, Will (1996), Ciudadania multicultural, Barcelona: Paidós.

Labov, William (1985), "La lógica del inglés no estándar", en Revista Educación y Sociedad, núm. 4, Madrid.

Lambert, Wallance E. (1981), "Bilingualism and language adquisition", en Winitz, Harris [ed.], Native language and foreign language adqusition, Nueva York: The New York Academy of Science. 
María Jiménez-Delgado. Discursos interculturales y prácticas asimilacionistas: algunas contradicciones en el sistema educativo español

Liégois, Jean-Pierre (1998), Minorías y escolaridad. El caso del pueblo gitano, Madrid: Centre de Recherches Tsiganes/Presencia Gitana.

Martín Criado, Enrique (2010), La escuela sin funciones. Critica de la sociología de la educación critica, Barcelona: Bellaterra.

Martín Rojo, Luisa [dir.] (2003), ¿Asimilar o integrar? Dilemas ante el multilingüismo en las aulas, Madrid: Centro de Investigación y Documentación Educativa (CIDE).

Matencio-López, Rita et al. (2015), "Percepción del profesorado sobre concepciones profesionales ante la diversidad cultural escolar", en Convergencia. Revista de Ciencias Sociales, núm. 67, México: Universidad Nacional Autónoma de México.

Naïr, S. (2010), La Europa mestiza. Inmigración, ciudadanía, codesarrollo, Barcelona: Galaxia Gutenberg, Círculo de Lectores.

Park, Robert E. y Ernest Burgess ([1924] 1970), Introduction to the science of sociology, Chicago: University of Chicago Press.

Peñalva Vélez, Alicia (2003), La educación intercultural como modelo de análisis de la realidad. Un estudio a partir de la percepción del alumnado y de lo que se refleja en los materiales curriculares de ciencias sociales de la ESO, España: Doctoral Thesis, UPNA.

Portes, Alejandro (2004), Un diálogo transatlántico: el progreso de la investigación y la teoría en el estudio de la migración internacional. CMD Working Paper, Princeton University.

Portes, Alejandro y Rubén G. Rumbaut (2010), Legados: la historia de la segunda generación inmigrante, Barcelona: Hipatia.

Rawls, John (1989), “The Domain of the Political and Overlapping Consensus”, en New York University Law Review, núm. 64/2, Nueva York, EUA.

Rodríguez, Fernando (2011), “Al-Andalus, España y la inexistencia de las culturas”, en Revista de Occidente, núms. 362-363, Madrid: Arce.

Sartori, Giovanni (2003), ¿Qué es la democracia?, Madrid: Taurus.

Savater, Fernando (2004), "Idolatría de la diversidad”, en El País, 1 de julio de 2004.

Siguán, Miquel (1998), La escuela y los inmigrantes, Barcelona: Paidós.

Terrén, Eduardo (2001), "La asimilación cultural como destino. El análisis de las relaciones étnicas en Robert Park”, en Sociológica. Revista de Pensamiento Social, núm. 4, España: Universidad da Coruña.

Torres, Jurjo (1992), El curriculum oculto, Madrid: Morata.

Touraine, Alain (2002), A la búsqueda de si mismo: diálogo sobre el sujeto. Barcelona: Paidós.

\section{Recursos electrónicos}

Álvaro, Mónica (2012), Análisis y evaluación crítica del material curricular utilizado en el área de conocimiento del medio natural, social y cultural: libros de texto e interculturalidad, Universidad de Valladolid. Disponible en http://uvadoc.uva.es/handle/10324/1440 [11 de enero de 2014].

Jiménez-Delgado, María (2012), La generación puente: la educación de las jóvenes de origen marroqui. Un estudio sociológico, Universidad de Alicante. Disponible en: http://hdl. handle.net/10045/23653 [21 de enero de 2014]. 
MEC (Ministerio de Educación y Ciencia) (2014), Las cifras de la educación en España. Curso 2011-2012 (Edición 2014). Disponible en: http://www.mecd.gob.es/serviciosal-ciudadanmecd/estadisticas/educacion/indicadores-publicaciones-sintesis/cifraseducacion-espana/2014.html [12 de enero de 2014].

Terrén, Eduardo (2005), “¿Por qué se desprecia tanto la asimilación cultural? Algunas enseñanzas de la investigación sobre las segundas generaciones”, en Conferencia Sociología de la Educación, Universidad de Salamanca (publicada en actas). Disponible en: http://campus. usal.es/ aeduardoterren/Documentos/Por_que_\%20se\%20desprecia\%20_tanto_\%20 la\%20_asimilacion\%20_cultural_Eduardo_Terren.pdf [12 de enero de 2014].

Thomas, Holli (2004), Cosmopolitanism and cultural diversity, Comunicación a 2nd Global Conference: Interculturalism: exploring critical issues, Viena, 2nd-4th December 2004. Disponible en http://inter-disciplinary.net/ati/diversity/interculturalism/ic2/ thomas\%20paper.pdf [12 de enero de 2014].

\section{Anexo}

\section{Tabla 1}

\section{Teorías y modelos educativos}

¿Se facilita el mantenimiento de la identidad y las características culturales y lingüísticas minoritarias?

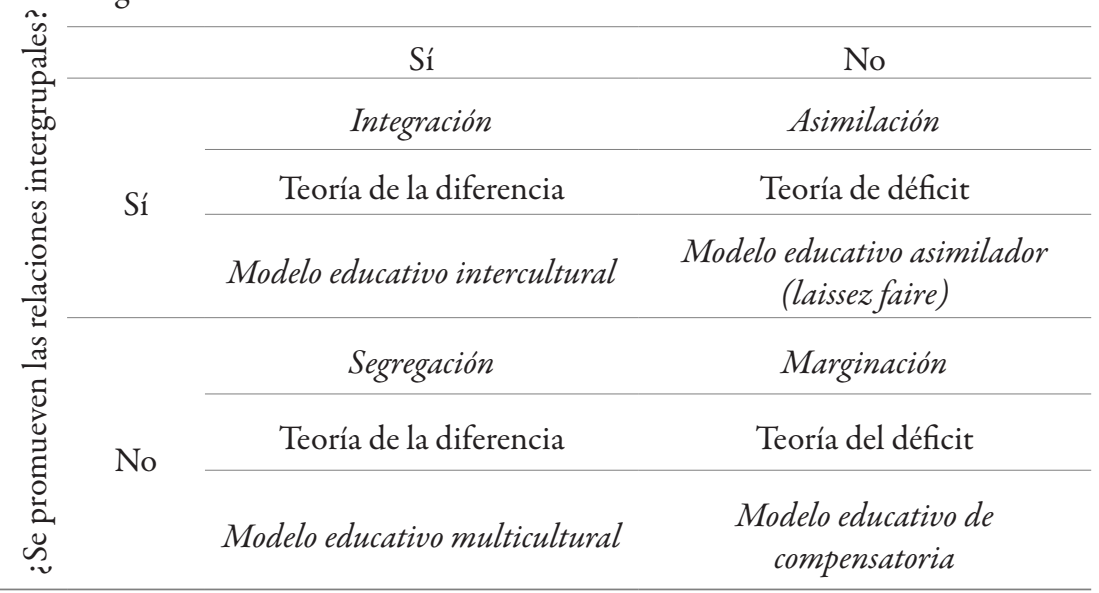

Fuente: Martín (2003). 
María Jiménez Delgado. Licenciada en Psicopedagogía y Doctora en Sociología. Profesora de Sociología de la Educación en la Universidad de Alicante, España. Es directora del grupo de investigación "Observatorio Sociológico de la Educación”. Líneas de investigación: educación, género, desigualdad e inmigración. Dirige el Proyecto $\mathrm{I}+\mathrm{D}+\mathrm{i}$ “Género, educación e igualdad (GEI): Éxito escolar, igualdad e inserción socio-laboral de las mujeres jóvenes de origen magrebí” (2013-2015). Publicaciones recientes: La generación puente: la educación de las jóvenes de origen marroqui. Un estudio sociológico, Universidad de Alicante (2012); “Cómo construir un currículo intercultural para una escuela democrática”, en Investigar el Cambio Curricular en el Espacio Europeo de Educación Superior, Marfil (2007); "El debate en el Campus Virtual: un instrumento para la educación universitaria”, en Recent Research Developments in Learning Technologies, Extremadura, España: Formatex (2005).

Recepción: 18 de febrero de 2015.

Aprobación: 9 de febrero de 2016. 
